\title{
INTER-LANGUAGE VOWEL PERCEPTION AND PRODUCTION BY KOREAN AND JAPANESE LISTENERS
}

\author{
John C.L. INGRAM and See-Gyoon PARK \\ Department of English \\ University of Queensland \\ Brisbane 4072 AUSTRALIA
}

\begin{abstract}
This paper investigates the influence of phonological learning upon the perception of non-native vowels. Four groups of Korean and Japanese English learners, at two levels of English experience, and a group of older monolingual Korean listeners were assessed on the perception and production of Australian English monophthongal front vowels: /i: ı e æ a:/.

Korean is of interest, because of a recent phonological merger of two front vowels $(/ \mathrm{e} /$ and $/ \varepsilon /)$, which has produced a generation split among speakers of Seoul dialect above and below 45-50 years of age (Hong, 1991). The present study is the first reported case of how a phonemic merger, resulting in cross-generation differences within a speech community, can influence speakers' perception and production of non-native vowels. The effects of phonological learning on vowel perception were also observed in the tendency of the Japanese, but not the Korean listeners, to normalise tokens of non-native vowels for speaker-dependent durational variation, consistent with the respective phonological roles of vowel length in Japanese and Korean.
\end{abstract}

\section{INTRODUCTION}

Both Japanese and Korean learners have difficulty distinguishing between the Australian English front vowels /e/ and /æ/, but for different reasons. Japanese has five monophthongal vowels (/i//e/ /a/ /o/ / $/ \mathrm{m} /$ ), with contrastively long and short variants. Specifically, it has no phonemic target, like Aust. English /æ/, which falls between /e/ and /a/ on the vowel chart. The case of Korean is complicated by an ongoing sound change. Older speakers of Seoul dialect, possess a mid-low front vowel, usually represented $/ \varepsilon /$, which contrasts with Korean /e/ and /a/, in a manner similar to Australian English /æ/. However, younger speakers have lost the phonological contrast between a mid and a low-mid front vowel, which is preserved in the speech of middle and older aged speakers. By comparing younger and older Koreans' perception of Australian English front vowels, it was hoped to obtain information on how the loss of a phonological contrast in the native language would affect the perception of a "foreign" vowel contrast in the second language.

Also relevant, are differences between the phonological status of vowel length in Japanese and Korean, and the implications that may follow for second language learners' perceptions of front vowel contrasts in Australian English. Whereas length contrasts are fundamental in Japanese, they play a marginal role in Korean vowel phonology. Also, long and short vowels are not distinguished in Korean orthography (Hangul), whereas they are in Japanese Kana scripts. Vowel length is an important exponent of the contrast between tense and lax vowels in Australian English, which are also accompanied by differences in vowel quality. The length/tenseness classification of Aust. English /æ/ is problematical. Phonetically, it clusters more closely with the long (tense) vowels in terms of duration (Fletcher, 1992). Phonologically, it patterns with the short (lax) vowels, in that it is not permitted in open monosyllables.

\section{IDENTIFICATION EXPERIMENT}

The first experiment tested non-native listeners recognition of the 5 Australian English front-mid vowels. A forced choice identification was conducted for the words heed, hid, head, had, hard, spoken by two male native speakers of Australian English, aged in their 40's, with tokens from the two speakers randomly interspersed on the 50 item test (5words $x$ 2speakers $x$ 5repetitons).

\subsection{Subjects}

The 4 learner groups: Korean Inexperienced (KI), Korean Experienced (KE), Japanese Inexperienced (JI) and Experienced (JE) were matched, across languages for age, occupation, and experience in English (Table 1).

$\begin{array}{lllll}\text { GROUP } & \text { N } & \text { AGE } & \text { OCCUPATION } & \text { ENGLISH EXPER. } \\ \text { Korean (KI) } & 5 & 24-28 & \text { Students } & <1 \text { year } \\ \text { Korean (KE) } & 5 & 25-38 & \text { Teachers } & >5 \text { years } \\ \text { Korean (KO) } & 4 & 51-58 & \text { Announcers } & \text { none } \\ \text { Japanese (JI) } & 5 & 21-23 & \text { Students } & <1 \text { year } \\ \text { Japanese (JE) } & 5 & 33-44 & \text { Teachers } & >\text { 5 years }\end{array}$

Table 1: Subject characteristics

The groups with less exposure to English were all students, aged in their twenties, who had been resident in Australia less than 12 months at time of testing. The groups with more English experience, were somewhat older, aged in their thirties; all were teachers of Korean or Japanese in Australian universities, who 
had been resident in Australia for more than 5 years. Subjects in these four groups used English on a daily basis. The difference in English fluency between the inexperienced and the experienced subjects was considerable. The fifth group (KO) was made up of non-English speaking Koreans in their 50's, who spoke a conservative (pre-merger) variety of Seoul dialect. Four were radio announcers and one an academic. All were tested in Korea. None had experienced intensive exposure to an English speaking environment.

\subsection{Results}

Table 2 summarises the vowel identifications, with a confusion matrix for each group of listeners. Table 3 presents a statistical analysis of the errors (the off-diagonal entries in Table 2). A series of one-way analyses of variance (ANOVA) was conducted, with the Error count as the dependent variable and Listener Group (KE, KI, KO, JI, JE) as the independent variable.

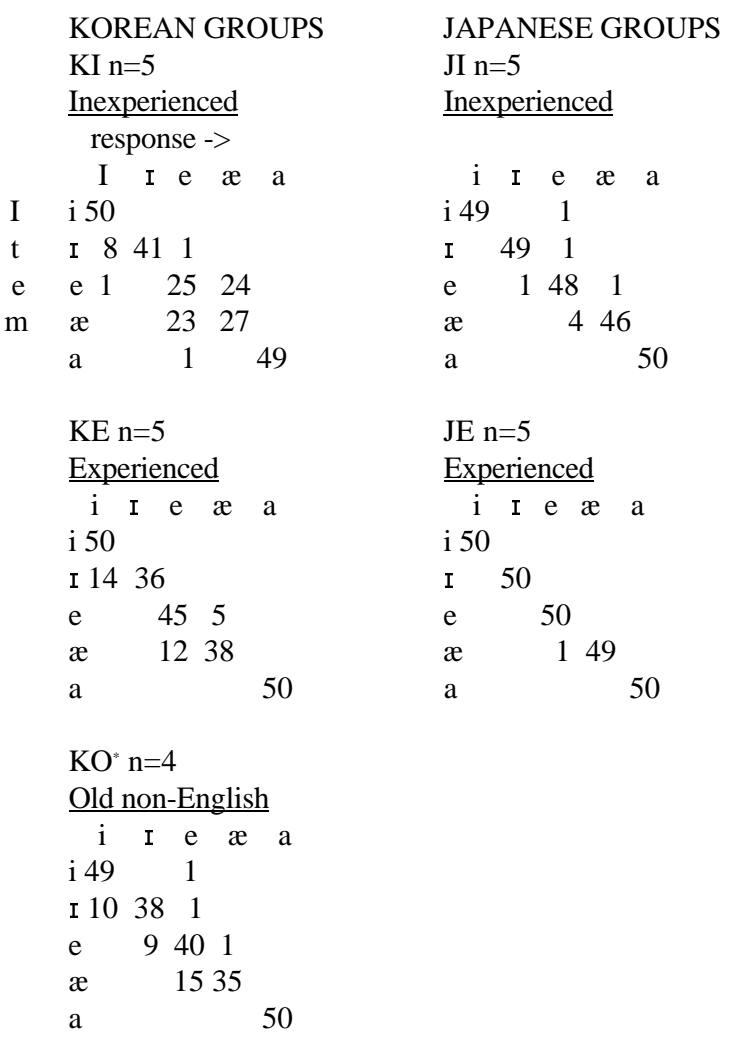

"Raw frequencies for the KO group were adjusted to facilitate comparisons with other groups, where $n=5$.

Table 2: Vowel identification confusion matrices

Despite their intensive exposure to English over several months, the young Korean Inexperienced (KI) group performed less well on the /e-æ/ contrast than the older Koreans (KO group) who spoke no English, indicating the significance of the phonological merger of $/ e-\varepsilon /$ in the native language for the perception of a foreign vowel contrast. However, it is notable that the $\mathrm{KO}$ listeners' possession of an L1 phonemic model for the foreign /eæ/ contrast, was not sufficient to confer an advantage over the Japanese listeners, who performed better than any of the Korean groups, despite the absence of any native target between /e/ and /a/. This suggested that the Japanese listeners were making more effective use of some phonetic cue(s) differentiating /e/ and /æ/ than were the Koreans. In particular, more effective use of durational cues was suspected.

\begin{tabular}{|c|c|c|c|c|}
\hline Dependent Var. & $\mathrm{ms}$ & $F$ ratio & o p level & Comparisons \\
\hline Total errors & 104.06 & 12.13 & $.00004 * *$ & $\mathrm{KI}>\mathrm{KE}, \mathrm{KO}>\mathrm{JI}, \mathrm{JE}$ \\
\hline Errors on [i:] & 0.05 & 1.32 & .29 & \\
\hline$" \quad[\mathrm{I}]$ & 6.97 & 3.49 & $027 *$ & $\mathrm{KE}, \mathrm{KO}, \mathrm{KI}>\mathrm{JI}, \mathrm{JE}$ \\
\hline$"$ [e] & 20.08 & 10.90 & $.00009 * *$ & $\mathrm{KI}>\mathrm{KO}, \mathrm{KE}>\mathrm{JI}, \mathrm{JE}$ \\
\hline " [æ] & 15.11 & 4.42 & $.01 * *$ & $\mathrm{KI}>\mathrm{KO}, \mathrm{KE}>\mathrm{JI}, \mathrm{JE}$ \\
\hline " [a:] & 0.04 & 0.46 & .46 & \\
\hline
\end{tabular}

Table 3: Summary ANOVAS Vowel identification by listener group.

Two approaches were taken to further analyse listeners' perceptual strategies: 1) an acoustic analysis of listeners' productions of the Australian English targets, and 2) an analysis of perceptual judgements made from the viewpoint of the listener's native language.

\section{PRODUCTION EXPERIMENT}

While the relationship between perception and production is complex (Pittam and Ingram, 1992), it is to be expected that cross-language differences in the perception of foreign vowels, will be mirrored in L2 learners' productions of those same vowels. Listeners who discriminate better among L2 vowels would be expected to produce them more accurately. Acoustic measurements of their production characteristics may provide indirect evidence of learners' perceptual representations of foreign sounds.

\subsection{Method}

The subjects were asked to read aloud the $/ \mathrm{hVd} /$ words that they had previously attempted to identify. Items were presented in a word list using standard English spelling. Each word was read five times in succession and the middle three tokens were used for analysis. Subjects productions were digitised at $10 \mathrm{kHz}$ sampling rate. The duration of each vowel was measured by hand from a dual spectrogram and waveform display (Speechstation ${ }^{\mathrm{TM}}$ ) and mid-vowel F1, F2, and F3 formant frequency measurements were taken, with the aid of an LPC smoothed spectral display. Formant measurements were taken to assess the accuracy of vowel quality production and duration measurements to assess the production of vowel length. Only the duration measurements are discussed here (see Ingram \& Park, submitted).

\subsection{Results}

Figure 1. shows a box plot of the durational characteristics the Korean and Japanese Australian English vowel productions. The 
Japanese showed a tendency to categorically distinguish long and short vowels, in their production of Australian vowels, but the Koreans did not. In particular, the Korean productions of Australian /æ/ suggested that this vowel had an intermediate status between long and short.

\section{Korean productions Japanese productions}

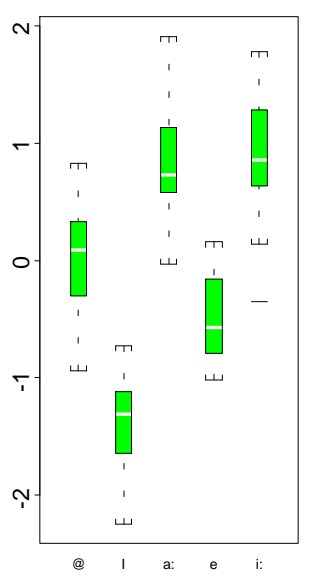

Fig

e 1:

Duration characteristics of Japanese and Korean Australian English vowel productions. Vowel durations (y-axis) normalised for speaker-dependent duration variation (Lobanov method). Note: @ = [æ].

The Japanese productions reflect categorical phonological contrasts between tense (long) and lax (short) vowels in Australian English. More precisely, they probably represent a projection of moraic contrasts of vowel length in Japanese upon the Australian targets. The Koreans, on the other hand, produced a set of vowels which were graded in their durational characteristics, monotonically reflecting the phonetic gradation of vowel duration which was present in the Australian target vowels (see Figure. 2).

\section{NATIVE RATINGS OF FOREIGN VOWELS}

In a third experiment, perceptual judgements of the same five Australian vowels was obtained from the standpoint of the listeners' native language. This experiment provided confirmation of the previous findings that the Koreans were responding to durational differences among the Australian vowels at a phonetic level, whereas the Japanese were responding at a phonological level, employing speaker normalisation strategies appropriate for the detection of phonological length contrasts.

\subsection{Method}

Listeners were asked to transcribe the stimuli in their native orthography (Kana or Hangul) and to note whether the vowel that they heard was short or long (geminate). Korean orthography provides distinct symbols for 4 of the 5 vowel targets represented in the experiment, including the 'merged' Korean /e/ and $/ \varepsilon /$ (i.e.: symbols for $/ \mathrm{i} /$, /e/, /æ/, and /a/, but not /I/). Subjects were instructed to use a hyphen to indicate "long vowels", following a special convention familiar to Korean readers, but not part of Hangul orthography. In the case of Japanese, only 3 orthographic symbols were available for representing different vowel qualities, (/i/, /e/, and /a/) but moraic length is represented orthographically in Kana.

\subsection{Results}

Table 5. shows how the Australian English vowels were perceptually categorised in terms of native phonological categories. The Responses to tokens produced by the two speakers A and B were tabulated separately. This revealed striking differences in the way that the Japanese and Korean listeners responded to tokens produced by the two speakers. The Japanese listeners categorised tokens of each vowel produced by each speaker consistently in the same way. Thus, /i/ was categorised as long and /I/ as short, regardless of the speaker. However, the Koreans' classification of particular vowel tokens was quite speaker-dependent. Comparison of the length classifications assigned by Korean listeners to each speaker's vowels, with the duration measurements shown in Figure 2 shows that Korean listeners were responding to absolute differences in token vowel duration. However, the Japanese listeners were apparently ignoring speaker-dependent differences in their perceptual categorisations of the stimuli.

\section{Length of Aust. English vowel tokens (unnormalised}

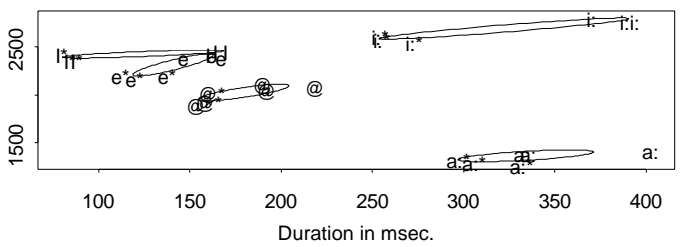

Vowel length speaker-normalised

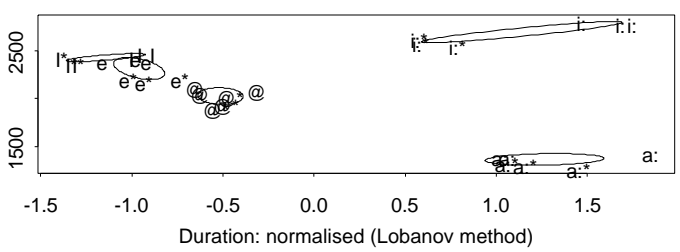

F i

gure 2: Duration characteristics of target vowels showing differences between the two Australian speakers (A and B; B = starred tokens). The upper graph shows un-normalised token durations plotted against F2. The lower graph shows token durations normalised for speaker-dependent differences (Lobanov method). Note: @=[æ].

The Japanese listeners employed vowel length to discriminate between Aust. English tense and lax vowels of similar quality. 
There was a high degree of agreement among the Japanese listeners and their judgements were not influenced by speakerdependent variation in vowel length. The Koreans, on the other hand, did not employ length contrasts to achieve perceptual classification of the Australian vowels to the same extent as the Japanese. There was less consensus in their judgements of vowel length and, in contrast to the Japanese, they were quite sensitive to speaker-dependent differences in vowel duration. Japanese subjects apparently employed speaker normalisation strategies, required for the perception of vowel length in Japanese, to the experimental stimuli, whereas the Koreans' showed sensitivity to the duration of particular stimuli and an absence of speaker normalisation that would normally be required for perception of phonologically contrastive vowel length.

\subsection{Discussion}

Differences in the phonological role of vowel length in Japanese and Korean proved to be decisive for the perception of the "foreign" Australian English front vowels, and the /e-æ/ contrast in particular. We found that Japanese, but not Korean listeners, applied perceptual processing strategies appropriate for the perception of phonological length contrasts in their native language to the perception of the Australian vowels. Specifically, Japanese listeners transferred normalisation strategies for handling speaker variation in vowel duration, used in the perception of Japanese short and long vowels, to the perception of tense/lax vowels in English. Korean listeners also responded to differences in vowel duration, but in a graded rather than categorical fashion, and did not normalise for speaker-dependent differences in stimulus duration.

\section{REFERENCES}

Bohn, O.-S., and Flege, J.E. (1992) The production of new and similar vowels by adult German learners of English. Studies in Second Language Acquisition, 14(2), 131-158.

Fletcher, J.E. and McVeigh, A. (1992) Towards a model of segment and syllable duration in Australian English. In J. Pittam (Ed.) Proceedings of the fourth Australian International Conference on Speech Science and Technology. Brisbane: A.S.S.T.A. pp. 28-33.

Hong, Y.-S. (1991) A sociolinguistic study of Seoul Korean. Korean Unification Studies, Series 12, Seoul: Research Centre for Peace \& Unification of Korea.

Ingram, J.C. and Park, S-G. (submitted) Interlanguage vowel perception and production by Korean and Japanese listeners. J. Phonetics.

Iverson, P. and Kuhl, P.K. (1995) Mapping the perceptual magnet effect for speech using signal detection theory and multidimensional scaling. J. Acoust. Soc. Am., 97, 553-562.

Pittam, J. and Ingram, J.C. (1992) Accuracy of perception and production of compound and phrasal stress by Vietnamese Australians, Applied Psycholinguistics, 13, 1-12.

Polka, L. (1995) Linguistic influences in adult perception of non-native vowel contrasts. J. Acoust. Soc. Am., 97(2), 12861296.
JAPANESE LISTENERS (JI+JE groups) Responses: native language categorisation

$\begin{array}{llrlcccc}\text { Target } & \text { Sp } & \text { i: } & \text { i } & \text { e: } & \text { e } & \text { a: } & \text { a Other } \\ \text { English } & & & & & & & \\ \text { i: } & \text { A } & 50 & & & & & \\ & \text { B } & 50 & & & & & \\ \text { I } & \text { A } & 5 & 45 & & & & \\ & \text { B } & 4 & 46 & & & & \\ \text { e } & \text { A } & & & & 50 & & \\ & \text { B } & & & & 50 & & \\ \text { æ } & \text { A } & & & 2 & 15 & 4 & 29 \\ & \text { B } & & & & 14 & 1 & 35 \\ \text { a: } & \text { A } & & & 1 & & 49 & \\ & \text { B } & & & & 50 & \end{array}$

KOREAN LISTENERS (KI+KE groups)

Responses: native language categorisation

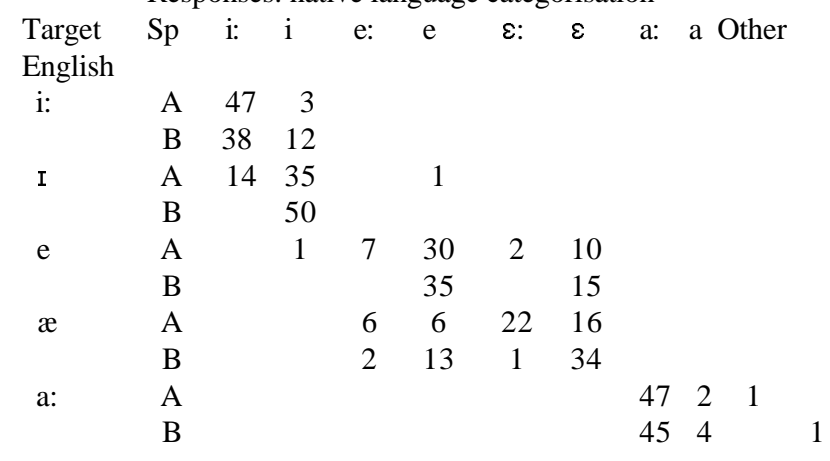

KOREAN MONOLINGUALS (KO group)

\begin{tabular}{|c|c|c|c|c|c|c|c|c|}
\hline \multirow{3}{*}{$\begin{array}{l}\text { Target } \\
\text { English }\end{array}$} & \multicolumn{2}{|c|}{ 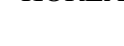 } & \multicolumn{6}{|c|}{ Responses: native language categorisation } \\
\hline & $\mathrm{Sp}$ & $\mathrm{i}:$ & i & e: & $\mathrm{e}$ & $\varepsilon:$ & $\varepsilon$ & a: a Other \\
\hline & & & & & & & & \\
\hline \multirow[t]{2}{*}{ i: } & A & 20 & & & & & & \\
\hline & B & 20 & & & & & & \\
\hline \multirow[t]{2}{*}{ I } & A & 13 & 7 & & & & & \\
\hline & B & 1 & 17 & & 2 & & & \\
\hline \multirow[t]{2}{*}{$\mathrm{e}$} & A & & & 4 & 12 & 1 & 3 & \\
\hline & B & & 1 & & 17 & & 2 & \\
\hline \multirow[t]{2}{*}{$æ$} & A & & & 1 & & 18 & 1 & \\
\hline & B & & & 1 & & 5 & 14 & \\
\hline \multirow[t]{2}{*}{ a: } & A & & & & & & & 20 \\
\hline & B & & & & & & & 20 \\
\hline
\end{tabular}

Table 5: Native language categorisations of Australian English vowel tokens. 